OPEN ACCESS

Edited by:

Binbin Zhang,

Institute of Oceanology (CAS), China

Reviewed by:

Yong Zou,

Shandong University, China

Da-Hai Xia,

Tianjin University, China

Tengfei Xiang,

Anhui University of Technology, China

*Correspondence:

Chao Yao

yaochao@cczu.edu.cn

Shuan Liu

liushuan@nimte.ac.cn

Specialty section:

This article was submitted to

Environmental Degradation of

Materials,

a section of the journal

Frontiers in Materials

Received: 31 August 2021

Accepted: 11 October 2021

Published: 12 November 2021

Citation:

Guo X, Xu H, Pu J, Yao C, Yang J and Liu S (2021) Corrosion Performance and Rust Conversion Mechanism of Graphene Modified Epoxy Surface

Tolerant Coating.

Front. Mater. 8:767776.

doi: $10.3389 /$ fmats.2021.767776

\section{Corrosion Performance and Rust Conversion Mechanism of Graphene Modified Epoxy Surface Tolerant Coating}

\author{
Xiaoping Guo ${ }^{1,2}, \mathrm{Hao} \mathrm{Xu}^{2}$, Jibin $\mathrm{Pu}^{2}$, Chao $\mathrm{Yao}^{1 *}$, Jing $\mathrm{Yang}^{3}$ and Shuan $\mathrm{Liu}^{2 *}$ \\ ${ }^{1}$ School of Petrochemical Engineering, Changzhou University, Changzhou, China, ${ }^{2}$ Key Laboratory of Marine Materials and \\ Related Technologies, Zhejiang Key Laboratory of Marine Materials and Protective Technologies, Ningbo Institute of Materials \\ Technology and Engineering, Chinese Academy of Sciences, Ningbo, China, ${ }^{3}$ Hubei Huaqiang Technology Co., Ltd., Yichang, \\ China
}

A graphene modified epoxy surface tolerant coating was prepared, and the corrosion performance and rust conversion mechanism of the prepared composite coating on rusty carbon steel substrate was investigated. Scanning electron microscope (SEM), X-ray powder diffractometer (XRD), and infrared (IR) spectrum were used to confirmed the iron rust conversion performance by the reaction of phytic acid and rust. electrochemical impedance spectroscopy (EIS), polarization curve, and salt spray test were used to evaluate the corrosion resistance of low surface treatment coatings. Results indicated most of the rust were dissolved and transformed with the reaction of phytic acid and rust on the rusty carbon steel; graphene could effectively improve the compactness and protective performance of the epoxy surface tolerant coating.

Keywords: corrosion, surface tolerant coating, graphene, rusty, EIS

\section{INTRODUCTION}

Heavy anticorrosive coating technology is the most economical and popular protection technology to slow down the corrosion rate of marine steel structures (Arukalam et al., 2018; Zhu et al., 2020). However, in order to ensure the anticorrosive quality of the coating, the steel substrate needs to be sandblasted or shot blasted before construction, and in most cases, the surface cleanliness after treatment is required to meet the surface treatment level Sa2.5 specified in ISO 8501-1988. Sandblasting not only brings a lot of dust and noise pollution but also increases the construction cost. Due to the influence of construction conditions, coating conditions, and the changeable coastal weather, the marine steel structure cannot be coated immediately after sandblasting or can only be coated with rust (Lei et al., 2021; Oliveira et al., 2021). In particular, some dead corners of complex steel structures cannot be treated by traditional sand blasting; besides, in the actual outdoor coating construction, it is impossible to completely and thoroughly sandblast steel. Even after sandblasting, the steel surface still has various degrees of rust and is often in a high degree of moisture. Therefore, it is particularly important to develop a simple and efficient anticorrosion coating with low surface treatment for long-term anticorrosion of equipment in the marine environment (Liao and Lee, 2016; Feng and Yuan, 2020).

Low surface treatment coating is also called surface tolerance coating, which is an anticorrosive coating that can be applied on the corroded surface of steel with simple surface treatment or without treatment. Low surface treatment coating has excellent adhesion, wettability, permeability, and rust 


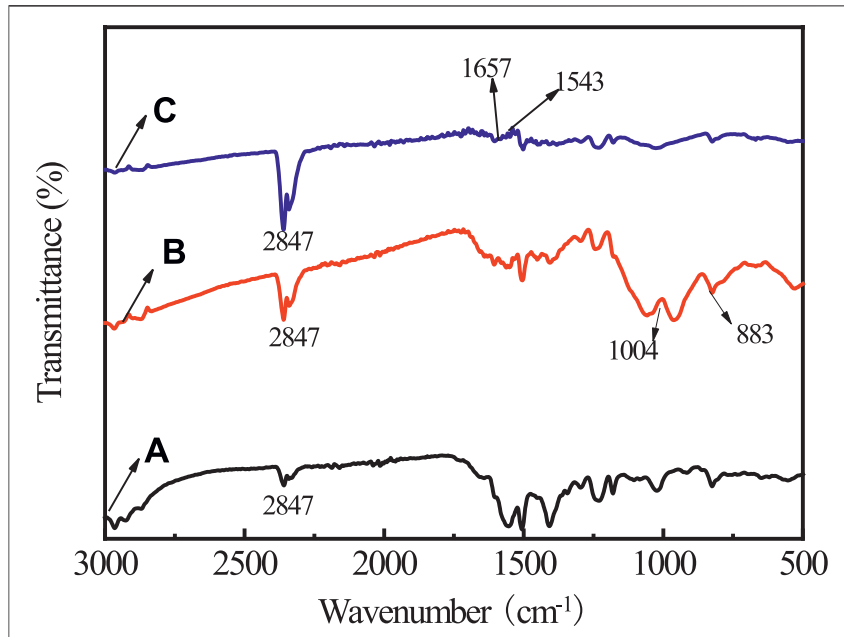

FIGURE 1 | The IR spectra for rusty carbon steel (A), PA dropped on rusty carbon steel (B), and PA/G/EP coating coated on rusty carbon steel (C).

conversion. Good wetting and permeability are the basis of low surface treatment coatings (Figueroa et al., 2020; Marano et al., 2020). On the one hand, the low surface treatment coatings contain active antirust pigments or rust conversion agents, which can transform active corrosion products, generate stable iron chelate, and become a part of the complete paint film as a way of inert fillers. On the other hand, adding chelating agent and corrosion inhibitor to rust primer can improve the passivation performance of metal substrate (Jiang et al., 2020; Chang et al., 2021).

Phytic acid (PA) molecule has six phosphate groups which can combine with metal cations; it is an environmentally friendly rust inhibitor. Graphene $(\mathrm{G})$ is the thinnest two-dimensional (2D) carbon material; its own unique nanostructure endows its perfect impermeability to any atoms and molecules under ambient conditions, and so $\mathrm{G}$ could be used as an excellent functional filler in anticorrosion coatings (Gu et al., 2015; Bai et al., 2021; Mu et al., 2021). In our previous research, we have confirmed that the original iron ions absorbed on rusty carbon steel surfaces could be transformed by PA, and a dense film was formed with the reaction of PA and rust (Xu et al., 2021). In this research, we prepared a $G$ modified epoxy surface tolerant coating using PA as a rust conversion agent and $\mathrm{G}$ as a functional filler. The corrosion performance of as-prepared surface tolerant coating on rusty steel was studied by means of electrochemical measurements in $3.5 \mathrm{wt}$ $\% \mathrm{NaCl}$ solution. The results of this paper may provide an insight on providing a simple and efficient protection technology for corroded metals in the marine environment.

\section{EXPERIMENTAL}

\section{Materials}

All reagents including PA solution (PA content: $70 \mathrm{wt} \%$ ) were purchased from Sigma-Aldrich and Aladdin and used without further purification unless otherwise noted. Epoxy resin (EP),

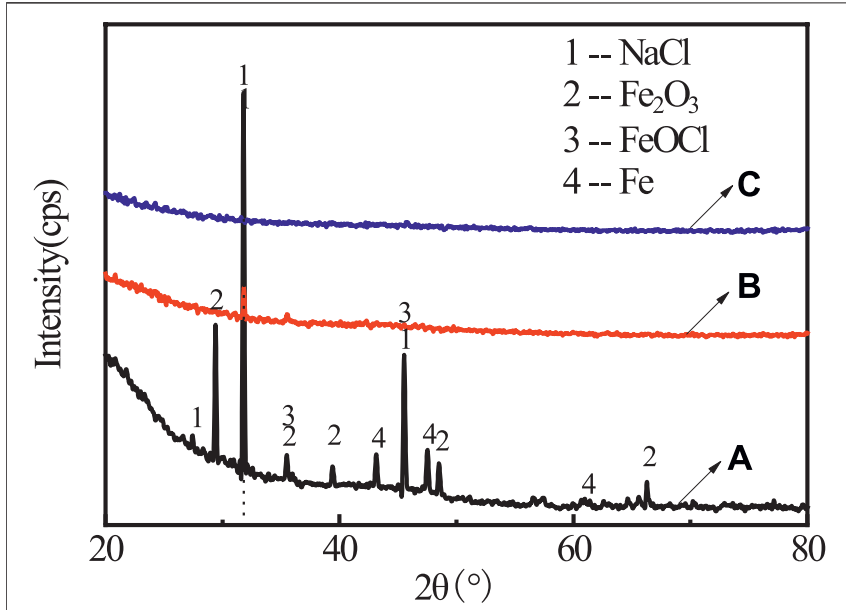

FIGURE 2 | The XRD spectra for rusty carbon steel (A), 5 wt\% PA solution dropped on rusty carbon steel (B), and PA/G coating coated on rusty carbon steel (C).

$\mathrm{C}_{12-14}$ alkyl glycidyl ether (AGE), and polyamide curing agent were purchased from Hubei Greenhome Materials Technology, Inc. $G$ powder (5-10 layers, $10-200 \mu \mathrm{m}$ diameter, 5-15 nm thickness, $99.5 \mathrm{wt} \%$ purity) was purchased from Ningbo Morsh Technology. Co., Ltd. Carbon steel $(1 \mathrm{~cm} \times 1 \mathrm{~cm} \times 1 \mathrm{~cm})$ was purchased from Yuxin Technology Co., Ltd. The polyo-phenylenediamine was prepared and used as $\mathrm{G}$ dispersant (Cui et al., 2019).

The rusty carbon samples were prepared by dropping $3.5 \mathrm{wt} \%$ $\mathrm{NaCl}$ solution onto the clean sample and allowing it to react for 30 days at ambient temperature. Some loose corrosion products were formed on the surface of carbon steel (namely, rusty carbon steel).

\section{Preparation of Graphene Modified Epoxy Surface Tolerant Coating}

Firstly, $0.5 \mathrm{~g}$ G power was ultrasonically dispersed by $0.01 \mathrm{~g}$ polyo-phenylenediamine in $20 \mathrm{ml}$ xylene solvent, and the mixture was stirred for $30 \mathrm{~min}$, then $0.12 \mathrm{~g} \mathrm{PA}, 20 \mathrm{ml} \mathrm{AGE}$, and $30 \mathrm{~g}$ EP were added to the above mixture and ground until paint fineness reached $50 \mu \mathrm{m}$. Finally, $20 \mathrm{~g}$ polyamide curing agent was added, and the mixture was stirred for $30 \mathrm{~min}$. The prepared composite coating (PA/G/EP) was applied to the rusty carbon steel cured at room temperature for $48 \mathrm{~h}$; the coating thickness was $60 \pm 2 \mu \mathrm{m}$. In the same way, a pure epoxy coating (EP) and PA with EP (PA/EP) were prepared and coated on rusty carbon steel at the same thickness.

\section{Material Characterization}

The rust and the PA chelate were analyzed by Intelligent Fourier Infrared Spectrometer (NICOLET 6700 FTIR) and X-ray powder diffractometer (Bruker-AXS D8 XRD). The cross-section surfaces of EP, PA/EP, and PA/G/EP were observed by scanning electron microscope (FEG 250 SEM). To prepare the cross-section surfaces, firstly, the coating was cured at $80^{\circ} \mathrm{C}$ for $24 \mathrm{~h}$, and 

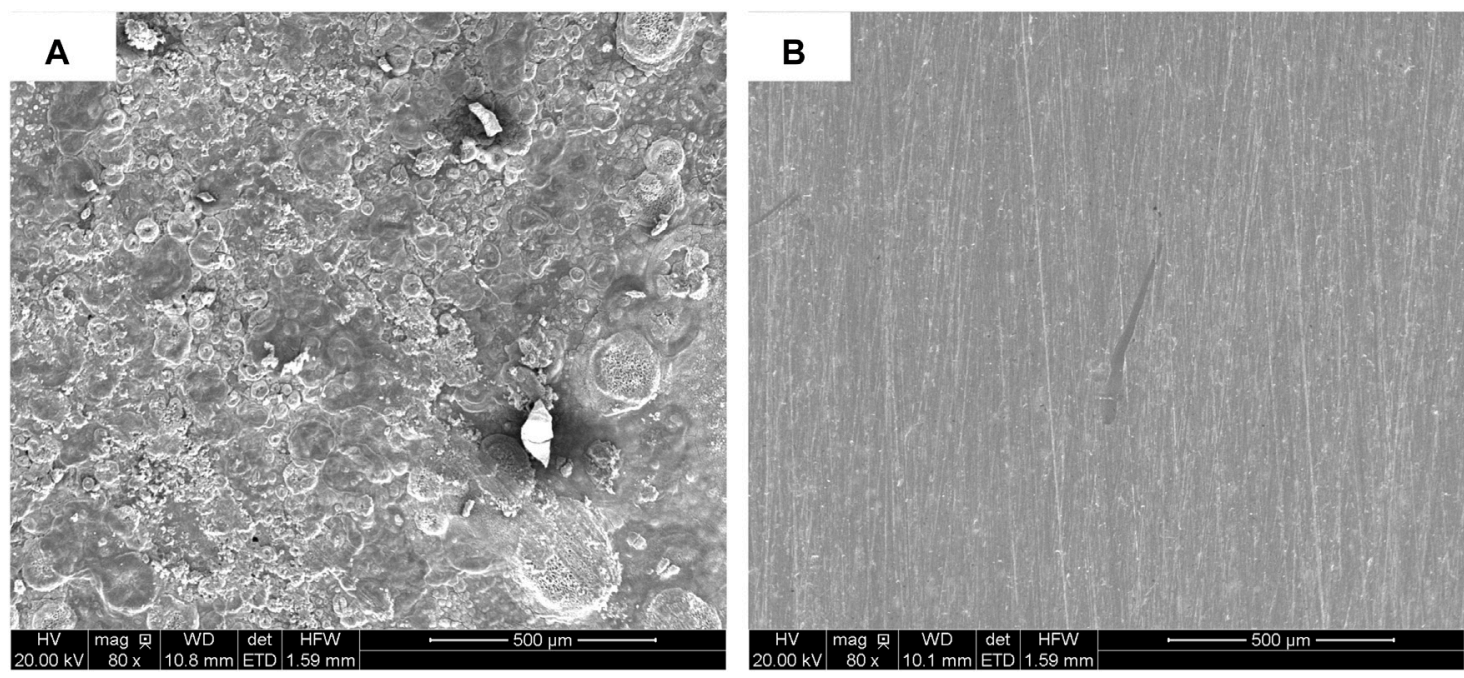

FIGURE 3 | SEM images of rusty carbon steel (A) and rusty carbon steel reacted with 5 wt \%PA solution for $24 \mathrm{~h}$ (B)
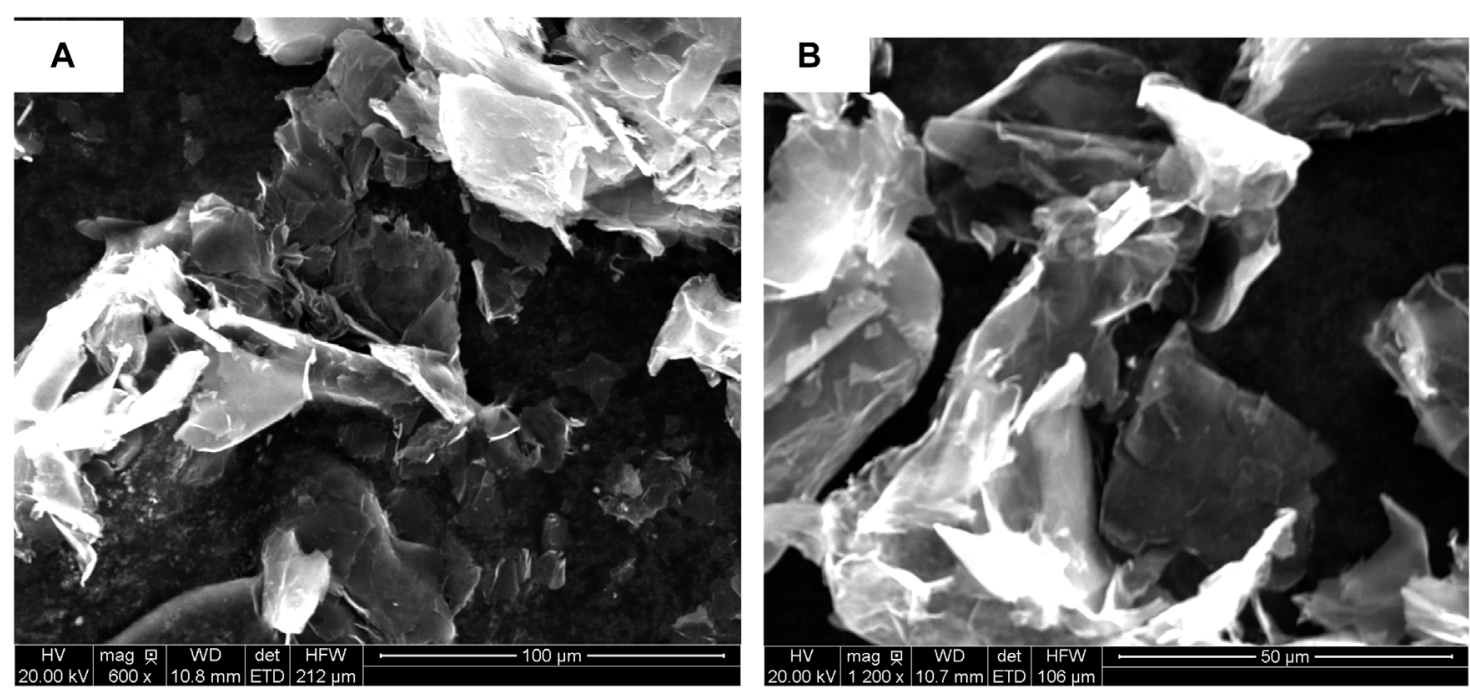

FIGURE 4 | SEM images of dispersed G in xylene solvent at low magnification (A) and high magnification (B).
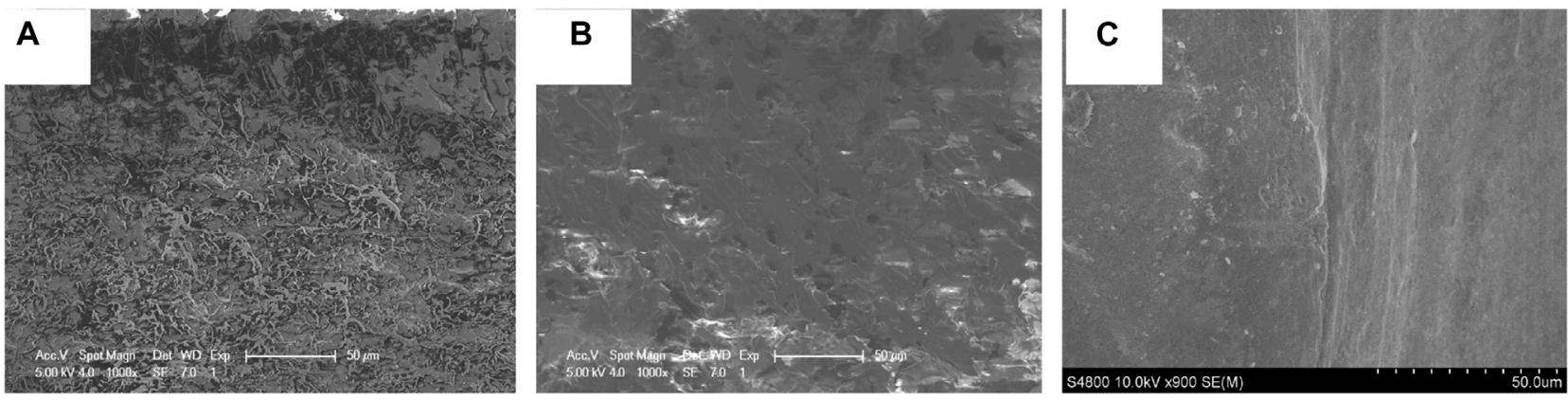

FIGURE 5 | The SEM cross-section images of prepared coatings, (A) pure EP, (B) PA/EP, and (C) PA/G/EP. 


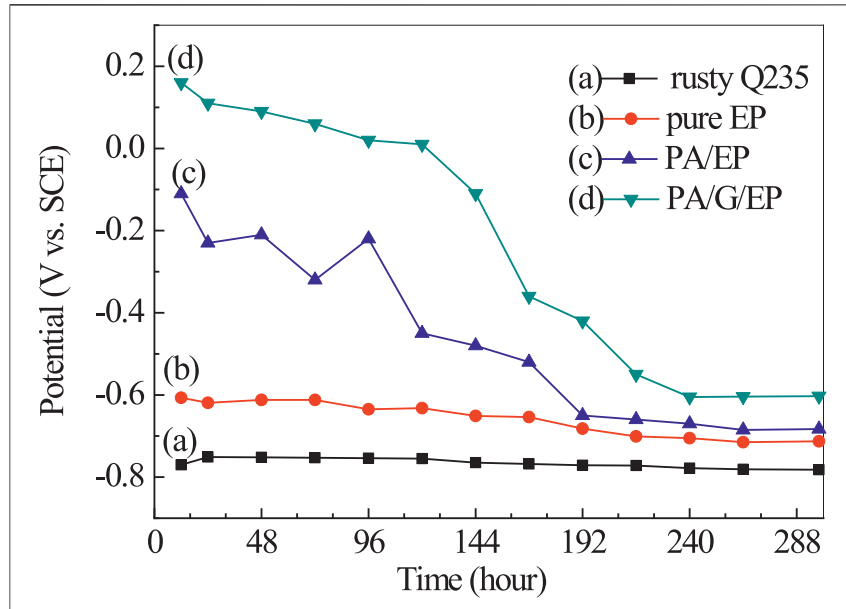

FIGURE 6 | The open circuit potential curves of rusty carbon steel (A), EP (B), PAVEP (C), and PA/G/EP (D) immersed in 3.5\% $\mathrm{NaCl}$ solution after $240 \mathrm{~h}$.

then the coating was quickly broken in a liquid nitrogen environment. Cross-section surfaces of different coatings were immediately treated with gold spraying to increase their conductivity (the thickness of the gold-plated layer was only 5-8 nm, which did not change the cross-section morphology of the prepared coatings), and at last the prepared cross-section surface samples were put in a vacuum chamber for SEM observation. The electrochemical test was performed at the electrochemical workstation (CHI-660E, China) using the three-electrode system. A platinum electrode was used as an auxiliary electrode, a calomel electrode was used as a reference electrode, and a carbon steel with $1 \mathrm{~cm}^{2}$ exposed area was used as a working electrode. The corrosive medium was $3.5 \mathrm{wt} \% \mathrm{NaCl}$ solution. The electrochemical impedance spectroscopy (EIS) curves after different immersion times were measured at an open circuit potential with an interference signal amplitude of $20 \mathrm{mV}$ and a frequency range of $100,000-0.01 \mathrm{~Hz}$. Electrochemical impedance fitting was performed using Zview software for data analysis. Three coating/electrode systems were prepared for each electrode, and the electrochemical test was repeated three times.

\section{RESULTS AND DISCUSSION}

\section{Transformation Performance of PA on Rusty Carbon Steel}

To investigate the transformation mechanism of PA on rusty carbon steel, infrared (IR) and XRD spectra of the rusty carbon steel, PA dropped on rusty carbon steel, and PA/G coating coated on rusty carbon steel are presented in Figures 1, 2, respectively. In the IR spectrum of rusty carbon steel (Figure 1A), the peaks at 883 and $787 \mathrm{~cm}^{-1}$ belonged to the bending vibration of $-\mathrm{OH}$ in a-FeOOH. The band of $682 \mathrm{~cm}^{-1}$ belonged to the bending vibration of $-\mathrm{OH}$ in $\beta-\mathrm{FeOOH}$, and the band around $745 \mathrm{~cm}^{-1}$ was due to the bending vibration of $-\mathrm{OH}$ in $\gamma$-FeOOH. When the
$5 \mathrm{wt} \%$ PA solution was dropped on the rusty carbon steel for $4 \mathrm{~h}$, the characteristic peaks of rusty carbon steel almost disappeared, and some new characteristic peaks located at 1,004 and $2,847 \mathrm{~cm}^{-1}$ appeared (Figure 1B), which corresponded to the $\mathrm{P}-\mathrm{O}$ stretching vibration and the stretching vibration of $\mathrm{OH}$ in the $\mathrm{P}-\mathrm{OH}$ group, indicating that $\mathrm{PA}$ could reacted with rust and has been absorbed on rusty carbon steel. When the PA/G/EP was coated on rusty carbon steel (Figure 2C), most of the characteristic peaks of rusty carbon steel cannot be detected. Some new absorption peaks at 1,657 and $1,543 \mathrm{~cm}^{-1}$ came from the carbon skeleton vibration of the $\mathrm{G}$ (Xu et al., 2021).

It can be found in the XRD (see Figure 2A) pattern that the rust mainly contained diffraction peaks of $\mathrm{NaCl}$ (PDF 05-0628), $\mathrm{FeOCl}$ (PDF 39-0612), $\mathrm{Fe}_{2} \mathrm{O}_{3}$ (PDF 16-0653), and Fe (PDF 501275). After adding $\mathrm{PA}$, only $\mathrm{NaCl}$ characteristic peak was left, indicating that most rust was converted by PA (Figure 2B). No obvious rust characteristic peak was found in Figure 2C. In order to investigate the change of surface morphology of rusty carbon steel after the reaction between PA and rust, $5 \mathrm{wt} \% \mathrm{PA}$ solution was directly dropped on the surface of rusty carbon steel. It could be seen that many corrosion pits appeared on the surface of rusty carbon steel (Figure 3A); when the PA reacted with the rust for $24 \mathrm{~h}$, the corrosion pits almost disappeared and the surface roughness significantly decreased (Figure 3B), indicating that the PA has excellent rust conversion performance.

Generally, coatings with good physical barrier properties have excellent protective properties, and the dispersion state of fillers in composite coatings has a significant impact on the physical barrier properties of coatings (Liu et al., 2013b). In order to observe the dispersion state of $\mathrm{G}$ and PA in the composite coating, SEM was used to observe the dispersion performance of $G$ in xylene solvent and the cross-section surface morphology of the coating, and the results are shown in Figures 4, 5, respectively. Figure 4 showed that the sheet structure of $G$ was dispersed uniformly by polyo-phenylenediamine in xylene solvent, and no obvious agglomeration of $\mathrm{G}$ could be found.

The cross-section surface of pure EP was relatively smooth, and there were fluvial cracks parallel to the direction of crack propagation on the surface (Figure 5A), which was typical of brittle thermosetting polymers section characteristics. After adding PA in pure EP (Figure 5B), the crack of PA/EP coating section was reduced compared with that of pure EP, and some small holes were observed in the coating. When the PA and well-dispersed G slurry were added in EP (Figure 5C), the cross-section of the PA/G/EP coating was smooth; no obvious agglomeration of $\mathrm{G}$ or small holes could be observed, indicating that $\mathrm{G}$ could effectively improve the compactness of the EP coating.

\section{Corrosion Performance of the G Modified Epoxy Surface Tolerant Coating}

Figure 6 presents the open circuit potential $\left(E_{\mathrm{OCP}}\right)$ variation of rusty carbon steel, EPPA/EP, and PA/G/EP coated on rusty carbon steel as a function of immersion time in $3.5 \% \mathrm{NaCl}$ solution. The $E_{\mathrm{OCP}}$ of rusty carbon steel was kept at $-0.782 \mathrm{~V}$ and was basically unchanged. The $E_{\mathrm{OCP}}$ of all coatings decreased to different degrees after the 


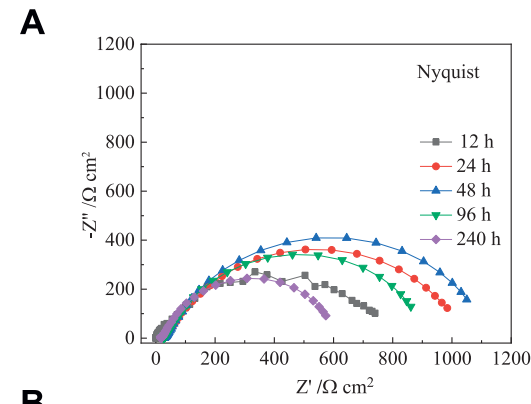

B

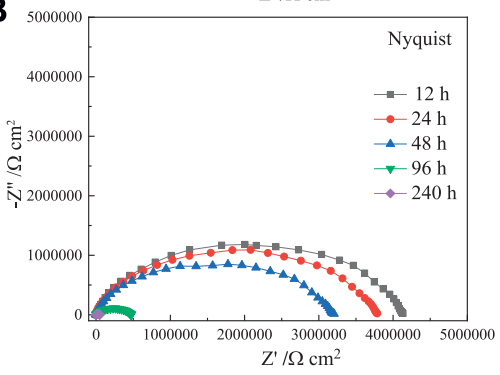

C

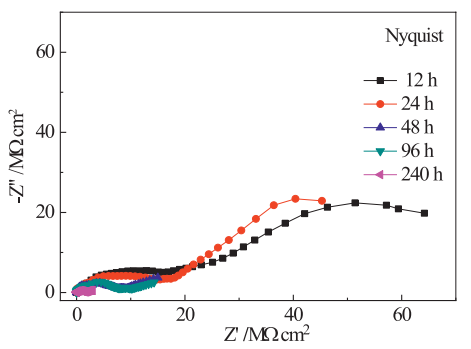

D

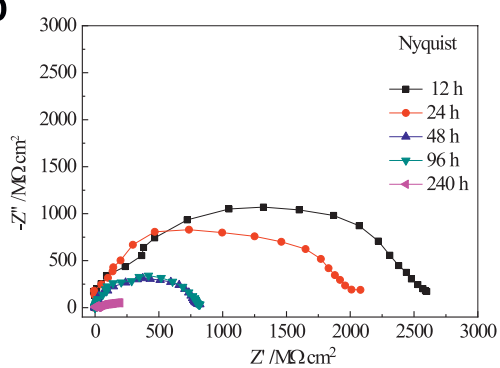

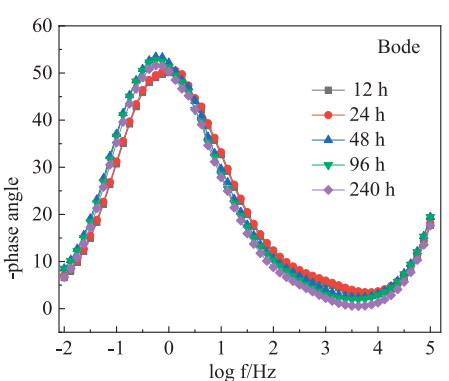
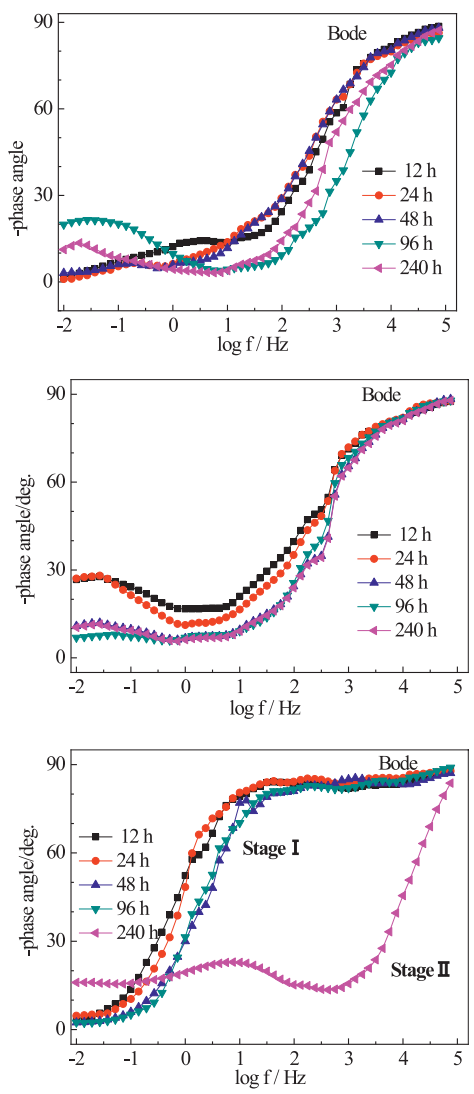
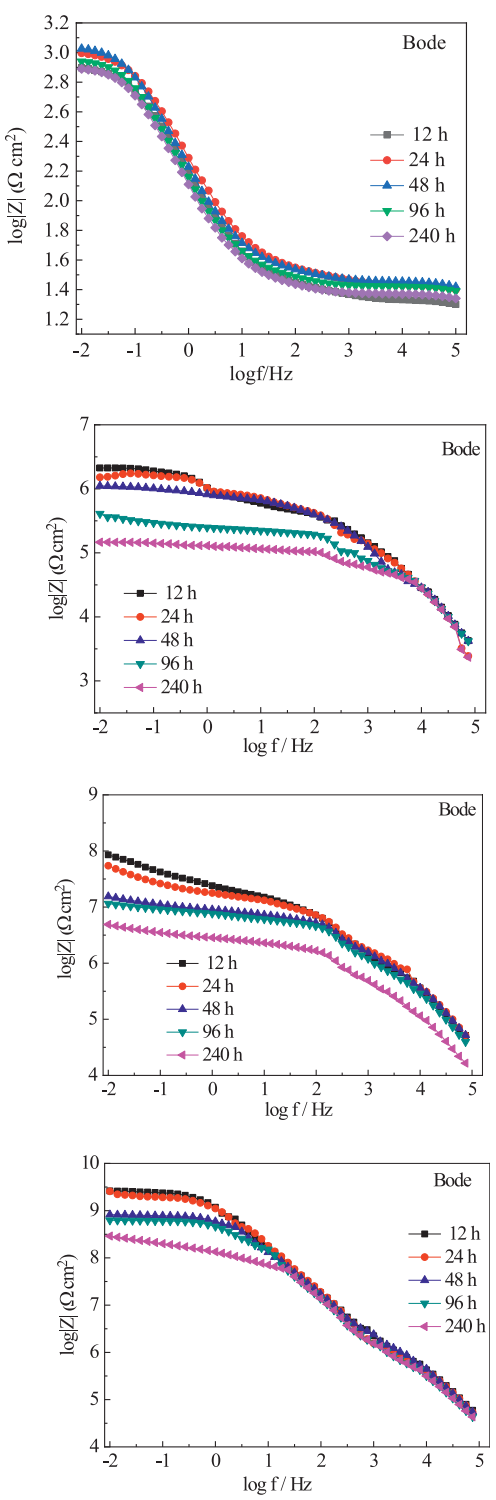

FIGURE 7 | The EIS of rusty carbon steel (A), EP (B), PA/EP (C), and PAG/EP (D) immersed in 3.5 wt\% NaCl solution after different times.

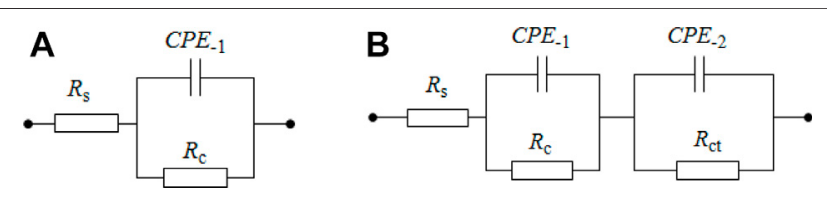

FIGURE 8 | The equivalent circuit used to fit the EIS data. (A) used for one time constant in EIS, (B) used for two time constants in EIS.

fluctuation at initial time and then remained basically unchanged after 240 h. Compared with pure EP, PA/EP and PA/G/EP exhibited much more enhanced $E_{\mathrm{OCP}}$. After $288 \mathrm{~h}$ immersion, compared to $\mathrm{EP}$, the positive shift of $E_{\mathrm{OCP}}$ as $0.11 \mathrm{~V}$ for PA/G/EP indicated that well-dispersed $\mathrm{G}$ has obvious corrosion inhibition, and this similar phenomenon has been reported by other researchers (Cui et al.,
2019). In our previous research, we confirmed that commercial G without dispersion was found to have almost no corrosion inhibition (Liu et al., 2016).

Nyquist and Bode plots are shown in Figure 7 for bare rusty carbon steel, EP, PA/EP, and PA/G/EP coated on rusty carbon steel after different immersion times in $3.5 \mathrm{wt} \% \mathrm{NaCl}$ solution, as EIS is one of the most intensive and nondestructive testing techniques for investigation and prediction of the anticorrosion performance of organic coating in aqueous solution (Liu et al., 2013a; Liu et al., 2013b). To quantitative analyze the corrosion resistance of these four systems, two appropriate equivalent circuits (Figure 8) were used to fit the EIS data, and the fitting corrosion parameters are listed in Table 1; (Xia et al., 2020). In Figure $\mathbf{6}, R_{\mathrm{s}}$ is the solution resistance, and $R_{\mathrm{c}}$ and $C P E_{-1}$ represent the coating resistance 
TABLE 1 | Electrochemical corrosion parameters fitted from the equivalent circuit.

\begin{tabular}{|c|c|c|c|c|c|c|c|c|}
\hline & \multirow[t]{2}{*}{ Time hours } & \multirow{2}{*}{$\frac{\boldsymbol{R}_{\mathrm{s}}}{\Omega}$} & \multirow{2}{*}{$\frac{C P E_{-1}}{n F / S^{(1-n 1)} \mathrm{cm}^{2}}$} & \multirow[t]{2}{*}{$n_{1}$} & \multirow{2}{*}{$\frac{R_{\mathrm{c}}}{\mathrm{M} \Omega \mathrm{cm}^{2}}$} & \multirow{2}{*}{$\frac{\mathrm{CPE}_{-2}}{\mu \mathrm{F} / \mathbf{S}^{(1-\mathrm{n} 2)} \mathbf{c m}^{2}}$} & \multirow[t]{2}{*}{$n_{2}$} & \multirow{2}{*}{$\frac{R_{\mathrm{ct}}}{\mathrm{M} \Omega \mathrm{cm}^{2}}$} \\
\hline & & & & & & & & \\
\hline \multirow[t]{5}{*}{ Rusty carbon steel } & 12 & 0.02 & 2,506 & 0.68 & $5.98 \times 10^{-5}$ & 235 & 0.89 & $1.12 \times 10^{-3}$ \\
\hline & 24 & 0.01 & 3,512 & 0.85 & $5.12 \times 10^{-5}$ & 335 & 0.66 & $1.08 \times 10^{-3}$ \\
\hline & 48 & 0.01 & 6,591 & 0.76 & $4.23 \times 10^{-5}$ & 285 & 0.86 & $9.56 \times 10^{-4}$ \\
\hline & 96 & 0.03 & 6,562 & 0.56 & $3.12 \times 10^{-5}$ & 269 & 0.78 & $7.73 \times 10^{-4}$ \\
\hline & 240 & 0.01 & 8,452 & 0.91 & $1.05 \times 10^{-5}$ & 398 & 0.96 & $6.32 \times 10^{-4}$ \\
\hline \multirow[t]{4}{*}{ EP } & 12 & 0.03 & 50.2 & 0.70 & 0.86 & 0.56 & 0.69 & 4.56 \\
\hline & 24 & 0.01 & 125 & 0.68 & 0.78 & 1.23 & 0.72 & 3.87 \\
\hline & 48 & 0.04 & 886 & 0.61 & 0.65 & 5.68 & 0.85 & 3.46 \\
\hline & 96 & 0.03 & 989 & 0.62 & 0.46 & 8.69 & 0.59 & 0.52 \\
\hline \multirow[t]{6}{*}{ PA/EP } & 240 & 0.02 & 1,023 & 0.71 & 0.23 & 9.98 & 0.62 & 0.12 \\
\hline & 12 & 0.01 & 19.7 & 0.95 & 18.6 & 0.0747 & 0.83 & 82.6 \\
\hline & 24 & 0.01 & 125 & 0.93 & 16.8 & 0.0859 & 0.77 & 78.4 \\
\hline & 48 & 0.03 & 234 & 0.91 & 11.3 & 0.161 & 0.82 & 15.2 \\
\hline & 96 & 0.01 & 376 & 0.84 & 9.53 & 0.562 & 0.84 & 13.5 \\
\hline & 240 & 0.02 & 758 & 0.88 & 7.56 & 0.983 & 0.79 & 3.56 \\
\hline \multirow[t]{5}{*}{ PA/G/EP } & 12 & 0.03 & 0.126 & 0.78 & 2,685 & - & - & - \\
\hline & 24 & 0.02 & 0.156 & 0.66 & 2,156 & - & - & - \\
\hline & 48 & 0.02 & 0.254 & 0.85 & 781.3 & - & - & - \\
\hline & 96 & 0.01 & 0.356 & 0.86 & 756.1 & - & - & - \\
\hline & 240 & 0.02 & 4.95 & 0.95 & 53.16 & 0.364 & 0.46 & 235.6 \\
\hline
\end{tabular}

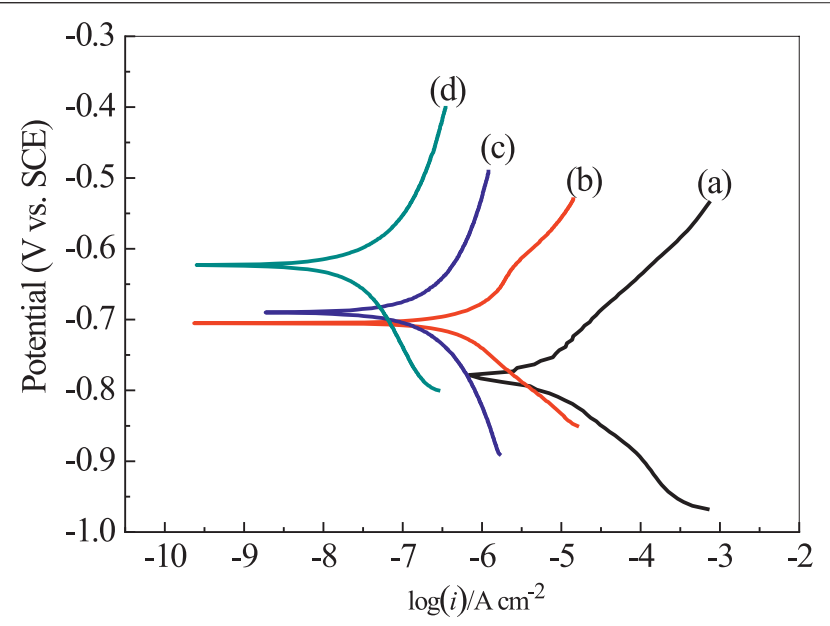

FIGURE 9|The polarization curves of rusty carbon steel (A), EP (B), PA EP (C), and PA/G/EP (D) immersed in $3.5 \mathrm{wt} \% \mathrm{NaCl}$ solution after $240 \mathrm{~h}$.

and coating capacitance, respectively. $R_{\mathrm{ct}}$ and $C P E_{-2}$ represent the charge-transfer resistance and double-layer capacitance, respectively (Wang et al., 2021; Cui et al., 2018). Figure 8A was used to fit the EIS data for PA/G/EP during the 96-h immersion, and Figure 8B was used to fit the EIS data which have two time constants (Pan et al., 2020).

Generally, the impedance modulus at the lowest frequency $\left(|\mathrm{Z}|_{0.01 \mathrm{~Hz}}\right)$ in Bode diagram can be used to evaluate the protective performance of the coatings. For the EIS results with two time constants, the time constant at the high frequencies corresponds to the capacitive behavior of the coating (or rust), and the time constant at the medium and low frequencies is assigned to the corrosion response of the metal substrates (Liu et al., 2012).
TABLE 2 | Corrosion parameters of rusty carbon steel, EP, PA/EP, and PA/G/EP immersed in $3.5 \mathrm{wt} \% \mathrm{NaCl}$ solution after $240 \mathrm{~h}$.

\begin{tabular}{|c|c|c|c|c|}
\hline & $E_{\text {corr }}$ & $i_{\text {corr }}$ & $\beta_{\mathrm{a}} \mathrm{mVdec}^{-1}$ & $-\beta_{\mathrm{c}} \mathrm{mVdec}^{-1}$ \\
\hline & V, vs.SCE & $\overline{\mu \mathrm{A} \mathrm{cm}-2}$ & & \\
\hline Rusty carbon steel & -0.778 & 13.2 & 73.9 & 61.8 \\
\hline EP & -0.705 & 0.813 & 121.7 & 105.2 \\
\hline PA/EP & -0.685 & 0.195 & 270.8 & 220.7 \\
\hline PA/G/EP & -0.624 & 0.031 & 285.2 & 221.1 \\
\hline
\end{tabular}

For the bare rusty carbon steel (Figure 7A), the radius of the two capacitive arcs decreased gradually, and the impedance modulus at low frequency domain $|\mathrm{Z}|_{0.01 \mathrm{~Hz}}$ decreased with time, indicating that the corrosion rate of rusty carbon steel increased in $3.5 \mathrm{wt} \% \mathrm{NaCl}$ solution. Without coating protection, the rusty carbon steel would corrode and fail in a short time in $3.5 \% \mathrm{NaCl}$ solution.

When the pure EP was coated on rusty carbon steel without surface treatment (Figure 7B), the porous rust in epoxy coating may reduce the compactness of paint film, form water-vapor channel, and then decrease its anticorrosion performance. The | $\left.\mathrm{Z}\right|_{0.01 \mathrm{~Hz}}$ of pure EP was only $3.56 \times 10^{5} \Omega \mathrm{cm}^{2}$ after $240 \mathrm{~h}$ immersion in $3.5 \mathrm{wt} \% \mathrm{NaCl}$ solution. Due to the water penetration and ionic species movement through the pure EP, the EP coating conductivity increased. The coating capacitance $\left(C P E_{-1}\right)$ increased from 50.22 to $1,023 \mathrm{nF} \mathrm{cm}^{-2}$, and the coating resistance $\left(R_{\mathrm{c}}\right)$ decreased from 0.86 to $0.23 \mathrm{M} \Omega \mathrm{cm}^{2}$ during $240 \mathrm{~h}$ of immersion in $3.5 \% \mathrm{NaCl}$ solution.

When the PA/EP is coated on rusty carbon steel (Figure 7C), the PA could react with rust, reduce the porosity and increase the adhesion of the coating to the rusty carbon steel, and then increase the compactness of paint film. The radius of two capacitive reactance arcs was doubled compared to pure EP. 

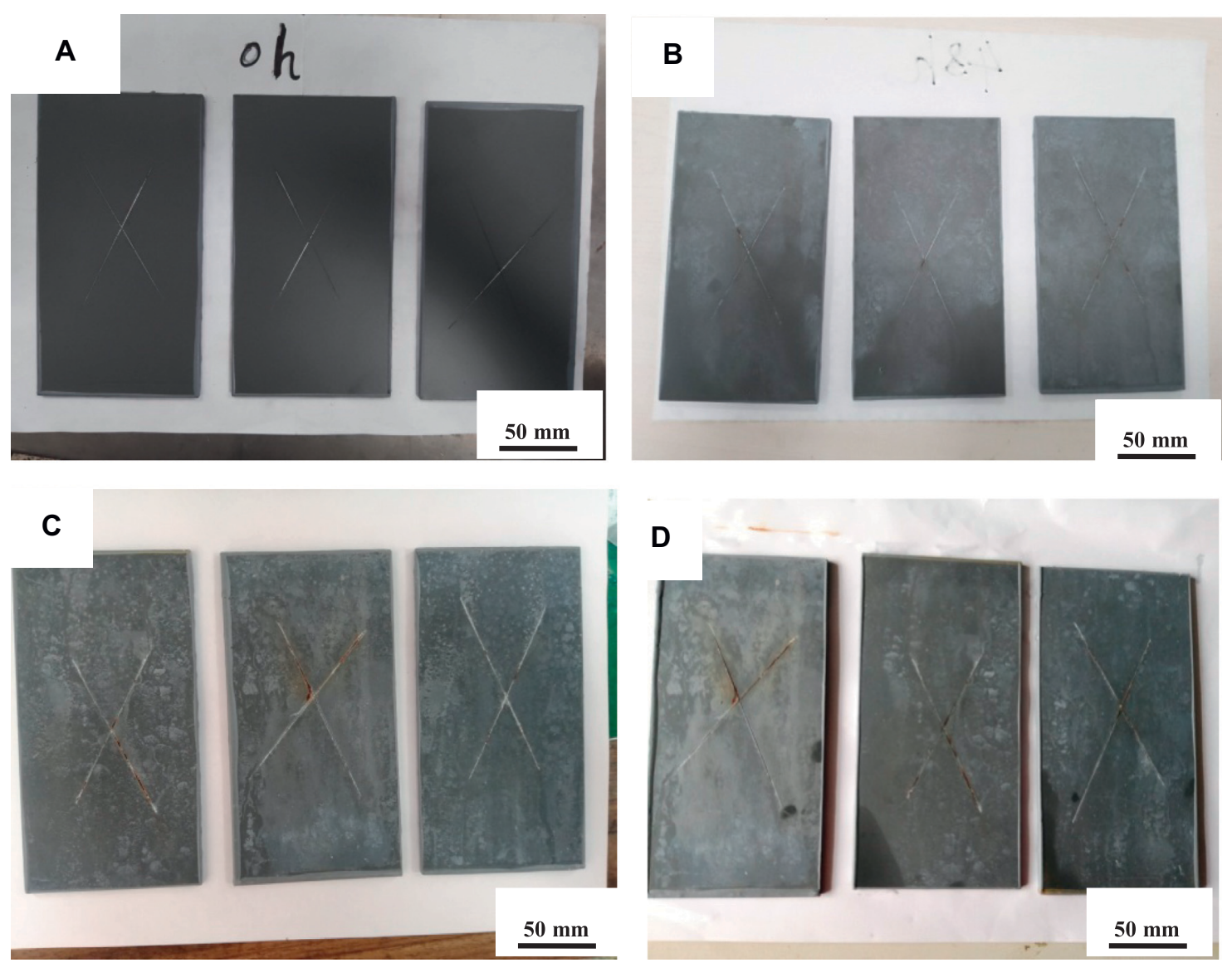

FIGURE 10 | Photographs of PA/G/EP coating immersed in salt spray chamber after different times. (A): 0 h; (B): 24 h; (C): 120 h; (D): 240 h.

However, there were still two time constants during the whole immersion times; the coating resistance $\left(R_{\mathrm{c}}\right)$ of PA/EP decreased from 18.6 to $1.56 \mathrm{M} \Omega \mathrm{cm}^{2}$ after $240 \mathrm{~h}$ immersion, indicating that water resistance of the PA/EP needs to be improved.

For PA/G/EP (Figure 7D), only one time constant was observed at the initial stage of $96 \mathrm{~h}$ immersion (Stage I), and then two time constants appeared after $240 \mathrm{~h}$ of immersion (Stage II). When the well-dispersed G is added into the EP, G can fill the structural and pinhole porosity of the EP and decrease the electrolyte diffusion towards the rusty carbon steel substrate, and the water diffusion coefficient is decreased greatly by the tortuous diffusion path (Liu et al., 2016). However, water molecules would gradually penetrate the coating with the extension of immersion time and accelerate the corrosion of the metal. Thus, two time constants (or two capacitive arcs) appeared after $240 \mathrm{~h}$ of immersion.

The pure EP and PA/EP coatings exhibit two time constants in short-term immersion, while the PA/G/EP remains one time constant in a high frequency range during 96-h immersion. The impedance modulus at low frequency $\left(|\mathrm{Z}|_{0.01 \mathrm{~Hz}}\right)$ can represent the corrosion protection of coating/metal system, which is in inverse proportion to the corrosion rate. The $|\mathrm{Z}|_{0.01 \mathrm{~Hz}}$ of the PA/G/EPcoated rusty carbon electrode was $5.9 \times 10^{8} \Omega \mathrm{cm}^{2}$ after $240-\mathrm{h}$ immersion (Figure 6D), which was far larger than that of pure EP $\left(2.1 \times 10^{5} \Omega \mathrm{cm}^{2}\right)$ and PA/EP $\left(7.3 \times 10^{6} \Omega \mathrm{cm}^{2}\right)$ coated rusty carbon electrodes after 240-h immersion (Figures 6B, C). These results indicated that $\mathrm{PA} / \mathrm{G} / \mathrm{EP}$ exhibited better corrosion protection for the rusty carbon steel than other coatings. The increase in impedance for PA/G/EP can be attributed to the hydrophobicity and barrier effects of $G$ well dispersed in EP. Moreover, PA/EP protects the rusty carbon steel against corrosion better than the pure EP does, mainly due to the passivation capabilities of the PA molecules.

Figure 9 presents the polarization curves of rusty carbon steel, EP, PA/EP, and PA/G/EP coated on rusty carbon steel immersed in $3.5 \mathrm{wt} \% \mathrm{NaCl}$ solution after $240 \mathrm{~h}$ at room temperature $\left(\sim 25^{\circ} \mathrm{C}\right)$. The corrosion parameters calculated from the Tafel regions are listed in Table 2 (Zhao et al., 2014). The corrosion current densities $\left(i_{\text {corr }}\right)$ calculated from Tafel regions of rusty carbon steel, EP, PA/EP, and PA/G/EP were 13.2, 0.813, 0.195, and $0.031 \mu \mathrm{A} \mathrm{cm}{ }^{-2}$, respectively. Compared to the bare rusty carbon steel, when the EP, PA/EP, and PA/G/EP were coated on rusty carbon steel, both of the absolute values of $\beta_{\mathrm{a}}$ and $\beta_{\mathrm{c}}$ increased, suggesting that the anodic oxidation and cathodic reduction reaction of rusty carbon steel were inhibited. It is important to note that the PA/G/EP exhibited more positive potential $(-0.624 \mathrm{~V})$ as compared to the rusty carbon steel $(-0.778 \mathrm{~V})$, and the $i_{\text {corr }}$ value of PA/G/EP $\left(0.031 \mu \mathrm{A} \mathrm{cm} \mathrm{cm}^{-2}\right)$ 
was almost two orders of magnitude less than that of the rusty carbon steel $\left(3.2 \mu \mathrm{A} \mathrm{cm} \mathrm{cm}^{-2}\right)$. The remarkably improved anticorrosion performance of PA/G/EP can be attributed to the synergistic effect of passivation performance of $\mathrm{PA}$ and physical barrier properties of G in the EP coatings.

\section{Salt Spray Tests}

Figure 10 shows photographs of PA/G/EP after different exposure times $(0,24,120$, and $240 \mathrm{~h})$ in neutral salt spray chamber. To accelerate the damage of salt spray to the paint film, a single-edged knife was used to cut " $x$ " on the surface of the coating. PA/G/EP compactly absorbed on the metal substrate and little corrosion was observed after $24 \mathrm{~h}$ (Figure 10B). It could be seen that some white sodium chloride deposited on the surface of the PA/G/EP film, and a few yellow rusty spots were observed near the scratches after $120 \mathrm{~h}$ (Figure 10C). After the PA/G/EP was kept in the salt spray chamber for $240 \mathrm{~h}$ (Figure 10D), yellow rust on the scratches increased; however, the PA/G/EP was intact without obvious corrosion or foaming phenomenon in the blank area. This phenomenon can be explained in that, on the one hand, G can improve the compactness of the PA/G/EP, making it difficult for the corrosion media (mainly including chloride ions and water molecules) to penetrate into the coating. On the other hand, the PA/G/EP has a good selfhealing ability, the $\mathrm{PA}$ in the coating has a good rust conversion effect of the coating, and PA can inhibit metal corrosion even at the scratches of PA/G/EP. The salt spray test results indicated the good anticorrosion performance of $\mathrm{PA} / \mathrm{G} / \mathrm{EP}$ coating.

\section{CONCLUSION}

1) A graphene modified epoxy surface tolerant coating was prepared by adding $G$ and PA in epoxy coating. Most of the rust was dissolved and transformed with the reaction of

\section{REFERENCES}

Arukalam, I. O., Oguzie, E. E., and Li, Y. (2018). Nanostructured Superhydrophobic Polysiloxane Coating for High Barrier and Anticorrosion Applications in marine Environment. J. Colloid Interf. Sci. 512, 674-685. doi:10.1016/j.jcis.2017.10.089

Bai, W., Ma, Y., Meng, M., and Li, Y. (2021). The Influence of Graphene on the Cathodic protection Performance of Zinc-Rich Epoxy Coatings. Prog. Org. Coat. 161, 106456. doi:10.1016/j.porgcoat.2021.106456

Chang, J., Wang, Z., Han, E.-H., Liang, X., Wang, G., Yi, Z., et al. (2021). Corrosion Resistance of Tannic Acid, D-Limonene and Nano-ZrO2 Modified Epoxy Coatings in Acid Corrosion Environments. J. Mater. Sci. Tech. 65, 137-150. doi:10.1016/j.jmst.2020.03.081

Cui, M., Ren, S., Pu, J., Wang, Y., Zhao, H., and Wang, L. (2019). Poly(o-phenylenediamine) Modified Graphene toward the Reinforcement in Corrosion protection of Epoxy Coatings. Corrosion Sci. 159, 108131. doi:10.1016/j.corsci.2019.108131

Cui, M., Ren, S., Zhao, H., Xue, Q., and Wang, L. (2018). Polydopamine Coated Graphene Oxide for Anticorrosive Reinforcement of Water-Borne Epoxy Coating. Chem. Eng. J. 335, 255-266. doi:10.1016/j.cej.2017.10.172
PA and rusty carbon steel. The well-dispersed G could inhibit the thermal shrinkage and improve the compactness of EP.

2) The $|Z|_{0.01 \mathrm{~Hz}}$ of the PA/G/EP-coated rusty carbon electrode was $5.9 \times 10^{8} \Omega \mathrm{cm}^{2}$ after 240 -h immersion, which was far larger than that of pure EP $\left(2.1 \times 10^{5} \Omega \mathrm{cm}^{2}\right)$ and PA/EP $\left(7.3 \times 10^{6} \Omega \mathrm{cm}^{2}\right)$ coated rusty carbon electrodes after $240-\mathrm{h}$ immersion.

3) When the PA/G/EP was coated on rusty carbon steel, both of the anodic oxidation and cathodic reduction reaction of rusty carbon steel were inhibited in $3.5 \mathrm{wt} \% \mathrm{NaCl}$ solution. The salt spray test results indicated the good anticorrosion performance of PA/G/EP coating.

\section{DATA AVAILABILITY STATEMENT}

The original contributions presented in the study are included in the article/Supplementary Material; further inquiries can be directed to the corresponding authors.

\section{AUTHOR CONTRIBUTIONS}

Conceptualization, XG; methodology, HX; formal analysis, XG and JY; data curation, XG and JP; writing-original draft preparation, $\mathrm{XG}$ and SL; writing-review and editing, $\mathrm{XG}, \mathrm{CY}$, and SL; supervision, CY and SL; funding acquisition, JP. All authors have read and agreed to the published version of the manuscript.

\section{FUNDING}

The authors gratefully appreciate the financial support provided by National Science and Technology Major Project (2017-VII0012-0107) and Zhejiang Key Research and Development Program (2019C03093).

Díaz, B., Figueroa, R., Nóvoa, X. R., Pérez, C., and Pintos, A. (2020). The Corrosion protection Afforded by a Commercial Rust Converter Doped with Graphene Oxide. Electrochimica Acta 342, 136096. doi:10.1016/j.electacta.2020.136096

Feng, L., and Yuan, P. (2020). Corrosion protection Mechanism of Aluminum Triphosphate Modified by Organic Acids as a Rust Converter. Prog. Org. Coat. 140, 105508. doi:10.1016/j.porgcoat.2019.105508

Gu, L., Liu, S., Zhao, H., and Yu, H. (2015). Facile Preparation of Water-Dispersible Graphene Sheets Stabilized by Carboxylated Oligoanilines and Their Anticorrosion Coatings. ACS Appl. Mater. Inter. 7, 17641-17648. doi:10.1021/acsami.5b05531

Jiang, C., Zhang, X., Wang, D., Zhang, L., and Cheng, X. (2020). Phosphate Conversion Coatings on $35 \mathrm{CrMnSi}$ Steels Subjected to Different Heat Treatments. Electrochemistry Commun. 110, 106636. doi:10.1016/ j.elecom.2019.106636

Lei, Y., Xiao, W., Peng, H., Yu, P., Cai, X., Luan, Z., et al. (2021). An Integrated Epoxy Rust Conversion Coating: Its Anticorrosion Properties and Rust Conversion Mechanism. J. Alloys Comp. 853, 157005. doi:10.1016/ j.jallcom.2020.157005

Liao, K.-W., and Lee, Y.-T. (2016). Detection of Rust Defects on Steel Bridge Coatings via Digital Image Recognition. Automation in Construction 71, 294-306. doi:10.1016/j.autcon.2016.08.008 
Liu, S., Gu, L., Zhao, H., Chen, J., and Yu, H. (2016). Corrosion Resistance of Graphene-Reinforced Waterborne Epoxy Coatings. J. Mater. Sci. Tech. 32, 425-431. doi:10.1016/j.jmst.2015.12.017

Liu, S., Gu, Y., Wang, S., Zhang, Y., Fang, Y., Johnson, D. M., et al. (2013b). Degradation of Organic Pollutants by a Co3O4-Graphite Composite Electrode in an electro-Fenton-like System. Chin. Sci. Bull. 58 (19), 2340-2346. doi:10.1007/s11434-013-5784-4

Liu, S., Sun, H., Sun, L., and Fan, H. (2012). Effects of pH and Cl- Concentration on Corrosion Behavior of the Galvanized Steel in Simulated Rust Layer Solution. Corrosion Sci. 65, 520-527. doi:10.1016/j.corsci.2012.08.056

Liu, S., Zhao, X.-R., Sun, H.-Y., Li, R.-P., Fang, Y.-F., and Huang, Y.-P. (2013a). The Degradation of Tetracycline in a Photo-Electro-Fenton System. Chem. Eng. J. 231, 441-448. doi:10.1016/j.cej.2013.07.057

Marano, C., Briatico-Vangosa, F., Marini, M., Pilati, F., and Toselli, M. (2009). Effects of Coating Composition and Surface Pre-treatment on the Adhesion of Organic-Inorganic Hybrid Coatings to Low Density Polyethylene (LDPE) Films. Eur. Polym. J. 45 (3), 870-878. doi:10.1016/j.eurpolymj.2008.11.028

Mu, J., Gao, F., Cui, G., Wang, S., Tang, S., and Li, Z. (2021). A Comprehensive Review of Anticorrosive Graphene-Composite Coatings. Prog. Org. Coat. 157, 106321. doi:10.1016/j.porgcoat.2021.106321

Oliveira, J. L., Skilbred, A. W. B., Loken, A., Henriques, R. R., and Soares, B. G. (2021). Effect of Accelerated Ageing Procedures and Flash Rust Inhibitors on the Anticorrosive Performance of Epoxy Coatings: EIS and Dynamic-Mechanical Analysis. Prog. Org. Coat. 159, 106387. doi:10.1016/j.porgcoat.2021.106387

Pan, C., Wang, X., Behnamian, Y., Wu, Z., Qin, Z., Xia, D.-H., et al. (2020). Monododecyl Phosphate Film on LY12 Aluminum alloy: pH-Controlled SelfAssembly and Corrosion Resistance. J. Electrochem. Soc. 167, 161510. doi:10.1149/1945-7111/abd3bb

Wang, Q., Wang, W., Ji, X., Hao, X., Ma, C., Hao, W., et al. (2021). Self-Healing Coatings Containing Core-Shell Nanofibers with $\mathrm{pH}$-Responsive Performance. ACS Appl. Mater. Inter. 13 (2), 3139-3152. doi:10.1021/acsami.0c18933

Xia, D.-H., Pan, C., Qin, Z., Fan, B., Song, S., Jin, W., et al. (2020). Covalent Surface Modification of LY12 Aluminum alloy Surface by Self-Assembly Dodecyl Phosphate Film towards Corrosion protection. Prog. Org. Coat. 143, 105638. doi:10.1016/j.porgcoat.2020.105638
Xu, H., Lu, G., Liu, S., Pu, J., Tian, S., Mao, C., et al. (2021). Anticorrosive Properties and Rust Conversion Mechanism of Phytic Acid-based Surface Tolerant Coating. Asia-pac J. Chem. Eng. 16, 2584. doi:10.1002/apj.2584

Ye, Y., Chen, H., Zou, Y., Ye, Y., and Zhao, H. (2020). Corrosion Protective Mechanism of Smart Graphene-Based Self-Healing Coating on Carbon Steel. Corrosion Sci. 174, 108825. doi:10.1016/j.corsci.2020.108825

Zhao, X., Liu, S., Wang, X., and Hou, B. (2014). Surface Modification of ZrO2 Nanoparticles with Styrene Coupling Agent and its Effect on the Corrosion Behaviour of Epoxy Coating. Chin. J. Ocean. Limnol. 32 (5), 1163-1171. doi:10.1007/s00343-014-3327-8

Zhu, Q., Li, E., Liu, X., Song, W., Li, Y., Wang, X., et al. (2020). Epoxy Coating with In-Situ Synthesis of Polypyrrole Functionalized Graphene Oxide for Enhanced Anticorrosive Performance. Prog. Org. Coat. 140, 105488. doi:10.1016/ j.porgcoat.2019.105488

Conflict of Interest: Author JY is employed by Hubei Huaqiang Technology Co., Ltd.

The remaining authors declare that the research was conducted in the absence of any commercial or financial relationships that could be construed as a potential conflict of interest.

Publisher's Note: All claims expressed in this article are solely those of the authors and do not necessarily represent those of their affiliated organizations or those of the publisher, the editors and the reviewers. Any product that may be evaluated in this article, or claim that may be made by its manufacturer, is not guaranteed or endorsed by the publisher.

Copyright (c) $2021 \mathrm{Guo}, \mathrm{Xu}, \mathrm{Pu}, \mathrm{Yao}$, Yang and Liu. This is an open-access article distributed under the terms of the Creative Commons Attribution License (CC BY). The use, distribution or reproduction in other forums is permitted, provided the original author(s) and the copyright owner(s) are credited and that the original publication in this journal is cited, in accordance with accepted academic practice. No use, distribution or reproduction is permitted which does not comply with these terms. 